\title{
Freqüência de diarréia em bezerros mestiços sob diferentes condições de manejo na região do médio Paraíba - Rio de Janeiro e Minas Gerais
}

Rita de Cássia Campbell Machado BOTTEON ${ }^{1}$ Paulo de Tarso Landgraf BOTTEON $^{1}$ Juracy de Castro Borba SANTOS JÚNIOR ${ }^{2}$ Melissa Hanzen PINNA ${ }^{3}$ Zelson Giácomo LÓSS ${ }^{1}$

\section{Correspondência para:}

Rita de Cássia Campbell Machado Botteon Departamento de Medicina e Cirurgia Veterinária - UFRRJ - BR 465 km 07 Seropédica-RJ, Cep: 23851-970 rbotteon@ufrrj.br

Recebido para publicação em 17/07/2007 Aprovado para publicação em 13/12/2007

\begin{abstract}
1 - Departamento de Medicina e Cirurgia Veterinária da Universidade Federal Rural do Rio de Janeiro, Seropédica-RJ

2 - Médico Veterinário da Faculdade de Medicina Veterinária de Valença, Valença - RJ 4 - Mestrado em Medicina Veterinária da Universidade Federal Rural do Rio de Janeiro, Seropédica-RJ
\end{abstract}

\section{Resumo}

As principais doenças que acometem bezerros e acarretam maiores gastos com medicação e perdas por mortalidade, são diarréia, tristeza parasitária e pneumonia. Em geral, estas enfermidades estão relacionadas ao manejo inadequado e precárias condições de higiene alimentar e ambiental. O presente trabalho foi desenvolvido visando verificar a freqüência de diarréia em bezerros mestiços submetidos a diferentes condições de manejo. O levantamento foi efetuado de agosto de 1998 a julho de 1999, envolvendo 1974 bezerros em 20 Unidades de Produção de Leite C, localizadas no Vale do Rio Preto, entre Valença (RJ), Rio das Flores (RJ) e Rio Preto (MG). A freqüência de casos de diarréia em relação a diferentes aspectos de manejo evidenciou menor ocorrência de diarréia entre os bezerros que permaneceram com a mãe após o parto por pelo menos 24 horas, nas unidades de produção que utilizaram o sistema de aleitamento natural e naquelas propriedades em que os bezerros receberam alimentação suplementar na forma de volumoso picado e concentrado fornecidos no cocho. Em geral, estas propriedades apresentaram em relação às demais, menos vacas em lactação, menor produção de leite e mão de obra do tipo familiar, que podem ter resultado em maior controle das medidas de higiene além de mais atenção e cuidados por parte dos criadores.

\section{Introdução}

A diarréia tem sido apontada como a mais importante enfermidade de bovinos jovens. ${ }^{1,2,3}$ Os índices de morbidade e mortalidade são variáveis segundo o sistema de criação, o agente causal e a capacidade de resposta do organismo. ${ }^{4}$ Mundialmente, estima-se uma perda entre $20 \%{ }^{5}$ e $52 \%{ }^{6}$ dos animais leiteiros devido à diarréia e um custo global com doenças entéricas equivalente a US\$33,46 bezerro/ano ${ }^{7}$. No Brasil, apesar das estimativas, não há dados oficiais sobre as taxas de morbidade e mortalidade de bovinos por diferentes enfermidades. Considerando o tipo de manejo dos rebanhos no país, acredita-se que os prejuízos sejam elevados. Em Minas Gerais, São Paulo e Rio de Janeiro, a diarréia, a tristeza parasitária e a pneumonia são apontadas como as principais causas de mortalidade e gastos com tratamento de bezerros. ${ }^{8,9,10,11,12,13,14,15,16}$ Alguns relatos $10,14,17,18$ indicam a mortalidade entre $10,3 \%$ e $34 \%$.

A síndrome diarréia neonatal ocorre como resultado da interação entre o bezerro, o meio ambiente, a nutrição e agentes infecciosos. ${ }^{4}$ Os principais agentes envolvidos são vírus (rotavírus e coronavírus), bactérias (Escherichia coli, Salmonella sp.e Clostridium perfringens) e 
protozoários (Eimeria sp) que atuam de forma isolada ou em associação, na dependência de fatores diversos ${ }^{19,20,21,22,23,24,25,26}$ Diarréia pode também ter origem não infecciosa, sendo nestes casos, os erros de manejo alimentar e higiênico as causas principais. ${ }^{25} \mathrm{~A}$ aplicação de medidas sanitárias, manejo e alimentação adequados, sobretudo nos primeiros dias de vida, pode reduzir significativamente a mortalidade e os gastos com tratamento de enfermidades em bezerros. ${ }^{3,27,28,29}$

A capacidade de identificação dos problemas e das prioridades nas propriedades passa por um conhecimento das condições particulares sob as quais se desenvolvem a exploração pecuária. A caracterização dos sistemas de produção de leite é importante para a identificação de gargalos do setor produtivo e implementação de projetos de desenvolvimento regional. No Brasil há grande diversidade sistemas de produção de leite. O padrão racial e, conseqüentemente, o manejo nutricional e sanitário são variáveis. A predominância é de rebanhos mestiços das raças Holandês e Zebu e o manejo adotado nas fazendas em geral varia com o grau de especialização do rebanho e, especialmente com animais HZ, há muita diferença entre propriedades quanto ao manejo sanitário e alimentação. Em vista dessas diferenças, não se dispõe de um critério único de tipificação dos sistemas vigentes no país e na região. Considerando que o manejo exerce influência direta ou indireta sobre a saúde do rebanho podendo prevenir ou expor os animais a fatores de risco, desenvolvemos o presente trabalho visando verificar os fatores relacionados e a freqüência de diarréia em bezerros mestiços submetidos a diferentes condições de manejo.

\section{Material e Método}

De uma relação de 63 Unidades de Produção de Leite (UPL), localizadas entre os municípios de Valença, Rio das Flores (RJ) e Rio Preto (MG), fornecedoras de leite a dois laticínios da região, foram selecionadas por indicação do Médico Veterinário da Secretaria de Agricultura de Valença, 32 propriedades nas quais foi aplicado um questionário para avaliação higiênicosanitária através de entrevista pessoal, em agosto de 1998. As entrevistas foram feitas com os proprietários ou encarregados, sempre pelo mesmo avaliador, inicialmente com cinco produtores para ajustes nos formulários, versando sobre dados de produção (área da propriedade, número de animais, volume de produção, tipo de mão de obra e a finalidade da produção), manejo e sistema de criação de bezerros (tempo de permanência com a mãe após o parto, forma de alimentação, tipo de bezerreiro e higiene ambiental).

Cada entrevista foi seguida de visita às instalações para observação das condições de criação. Para a análise das informações coletadas através da entrevista, construiu-se um banco de dados. Procedeu-se então à descrição dos dados para extrair as conclusões, priorizando-se as unidades de produção em que as respostas emitidas a cada uma das perguntas foram consistentes com as observações feitas. Após a primeira visita o grupo de propriedades foi reduzido para 20, concorrendo para este efeito a concordância entre as respostas emitidas e observações pessoais, a permissão para visitas mensais, as condições de acesso, proximidade entre os grupos e facilidade de obtenção de informações referentes à idade e identificação dos bezerros.

No contexto, as 20 propriedades que constituíram o grupo de estudo foram subdivididas quanto às características gerais da produção (média de produção diária de leite, número de vacas em lactação, tipo de mão de obra e número de bezerros nascidos no ano) em unidades de produção familiar (8), pré-empresarial (7) e empresarial (5) segundo critérios utilizados por Prado ${ }^{30}$.

Dentro de cada sistema, avaliaram-se os fatores específicos da forma de criação dos bezerros: tempo de permanência com a mãe após o parto (primeira mamada e 24 horas), forma de aleitamento (natural e no 
balde), idade ao desmame (90 a 120 dias e mais de 120 dias), tipo de bezerreiro (individual e coletivo), separação por idade (com ênfase aos recém nascidos), freqüência de higienização do bezerreiro e forma de suplementação dos bezerros (volumoso, volumoso + concentrado, volumoso + concentrado + mistura mineral). Embora não tenha sido intencional, em nenhuma das propriedades se utilizava vacinação contra agentes específicos de diarréia. $\mathrm{O}$ levantamento dos casos de diarréia ocorridos em cada propriedade foi efetuado de agosto de 1998 a julho de 1999, período em que foram realizadas 10 visitas a cada propriedade, em intervalos aproximados de um mês.

Após uma observação geral, foi anotado o total de bezerros em cada UPL, o número de animais com evidência clínica de diarréia, caracterizada por nádegas, jarrete ou cauda sujos de fezes e examinados individualmente todos os animais com idade entre 1 e 90 dias que se encontravam no bezerreiro no momento das visitas.

Durante o exame clínico, uma amostra de fezes foi obtida mediante estimulação retal, sendo observadas as características relativas ao aspecto, coloração, odor, quantidade, e presença de substâncias anormais. Dos animais com defecação voluntária, observou-se, além dos parâmetros acima, sinais de dor à defecação. Foram caracterizadas como diarréicas as fezes de consistência líquida ou pastosa mole ${ }^{4}$. A ocorrência de diarréia em relação ao tempo de permanência com a mãe após o parto, forma de aleitamento, idade ao desmame, tipo de bezerreiro, separação por idade, freqüência de higienização das instalações, forma de suplementação e características gerais da propriedade foi analisada estatisticamente a um nível de significância de $95 \%$ ( $\mathrm{p} \leq 0,05)$, pelo teste do Qui quadrado.

\section{Resultados e Discussão}

Foram examinados 1974 bezerros lactentes e 19,75\% (390) apresentaram fezes de consistência variando de mole $(8,4 \%)$ a líquida $(11,3 \%)$, características de diarréia ${ }^{4}$. Em geral, os dados de ocorrência de diarréia e outras enfermidades que acometem bezerros no Brasil são escassos. Estudos realizados por Sousa et al. ${ }^{12}$ apontaram a diarréia como um problema relativamente comum $(28 \%)$, especialmente nos primeiros meses de vida. Outros pesquisadores identificaram índices variando de 5,8 a $22 \%$ em diferentes condições de manejo. Portanto, o número de casos registrados no presente estudo está concordante com levantamentos regionais e confirmam a relevância da diarréia como enfermidade de bezerros lactentes.

Quanto às características gerais das propriedades, a análise entre os estratos evidenciou que diarréia foi menos freqüente $(p=0,00747)$ nas unidades de produção familiar $(18,3 \%)$, comparativamente aos sistemas pré-empresarial $(22,5 \%)$ e empresarial (19\%). As unidades de produção familiar apresentaram em relação às demais, menor número de bezerros nascidos no ano, menos vacas em lactação, menor produção diária de leite e mão de obra familiar que podem ter resultado em maior controle das medidas de higiene além de mais atenção e cuidados que em conjunto resultaram em menos diarréia.

Diferença significativa foi verificada quanto à ocorrência de diarréia em relação ao volume de produção de leite e número de bezerros, com porcentagem menor de bezerros acometidos nas UPL com produção menor que 250 litros/dia (11,90\%) e onde nasceram menos de 30 bezerros no ano $(14,73 \%)$, comparativamente aquelas UPL onde a produção foi maior que 250 litros $/$ dia $(p=0,0265)$ e nasceram entre $30 \mathrm{e}$ $50(17,54 \%)$ ou mais de $50(21,76 \%)$ bezerros por ano $(p=0,0279)$. Quanto ao número de vacas em lactação, a análise não evidenciou diferença significativa ( $\mathrm{p}=0,4831)$, embora diarréia tenha sido menos freqüente nas UPL com menos vacas em lactação em concordância com outros autores que registraram maiores índices de morbidade ${ }^{10}$ e mortalidade ${ }^{31}$ de bezerros em propriedades 
com rebanhos maiores. Segundo Lucci ${ }^{32}$, esses resultados podem ser decorrentes de dificuldades de manejo com maior número de animais, destacando-se a necessidade de número maior de pessoas envolvidas com a lida dos animais, e o aumento comum das fontes de infecção, o que está diretamente ligado à mortalidade dos bezerros, principalmente nos primeiros meses de vida. Comparando-se o tempo de permanência dos bezerros com a mãe após o parto e a ocorrência de diarréia, observouse que diarréia foi menos freqüente entre os bezerros que permaneceram com as mães por até 24 horas $(20,85 \%)$, porém sem diferença significativa $(p=0,3141)$ em relação àqueles que foram apartados logo após a primeira mamada $(19,01 \%)$. Esse fato está de acordo com o conceito geral de que a presença da mãe após o parto e ingestão adequada de colostro pode exercer influência sobre o desenvolvimento e ocorrência de enfermidades no período pósnatal ${ }^{3,28,29,33,34,35,36}$. Contudo, não somente $\mathrm{o}$ momento de ingestão, mas também a qualidade e a quantidade do colostro ingerido são aspectos decisivos para que o neonato adquira imunidade adequada no início da vida ${ }^{31,32,36,37,38,39}$. E ainda, a quantidade de imunoglobulinas requerida para adequada imunidade depende das condições de manejo e patogenicidade do agente $5,40,41,42,43$.

No presente trabalho, a análise estatística quanto à ocorrência de diarréia em relação às formas de aleitamento, evidenciou maior número de casos entre os bezerros alimentados no balde $(23,04 \%)$ ) com diferença significativa $(p=0,0432)$ em relação as UPL que utilizaram sistema de aleitamento natural $(18,75 \%)$, em concordância com relatos de Lucci $^{32}$. Dados recentes ${ }^{31}$ apontam para uma menor taxa de mortalidade em bezerros alimentados de forma artificial no período de colostro e durante o aleitamento, sugerindo que o fornecimento artificial de colostro, praticado no tempo correto e em quantidades adequadas, assegura a higidez do recém-nascido. No presente estudo, pode-se cogitar que as medidas de higiene e assepsia dos utensílios utilizados para o fornecimento do colostro e leite não garantiram o controle da carga patogênica, que, antes, ou juntamente com o colostro, foi ingerida pelo animal.

A taxa de mortalidade e a prevalência de enfermidades podem ser influenciadas pelo tempo de ocupação, condições de higiene e taxa de lotação do bezerreiro. Luccir $^{32}$ aponta para uma menor prevalência de enfermidades e menores taxas de mortalidade em animais desmamados precocemente, sugerindo que o desmame precoce exige mais atenção por parte dos criadores, melhores condições de higiene e mais tecnologia. Contraditoriamente, os dados obtidos no presente trabalho evidenciaram menor porcentagem de diarréia entre os bezerros desmamados tardiamente. Nas UPL que desmamaram até os 120 dias, $24,17 \%$ dos bezerros apresentaram diarréia, enquanto que nas condições em que os bezerros foram desmamados mais tarde, diarréia foi registrada em 18,18\% dos animais, com diferença foi significativa a um grau de confiança de $99 \%$ ( $p=0,0033$ ). Os dados sugerem que as medidas adotadas para efetuar desmama precoce, não foram efetivas no sentido de reduzir os índices de diarréia entre os animais. Neste contexto, os animais desmamados precocemente eram alimentados artificialmente, sendo necessário um questionamento sobre os cuidados na administração do leite, no que se refere à temperatura, horários, volume e posição do balde que podem exercer influência sobre os índices de diarréia, especialmente se o sistema adotado não respeitar normas de higiene e cuidados ${ }^{27,32}$. Vale ressaltar que embora os animais fossem desmamados em geral aos 120 dias ou após esse período, o levantamento dos casos de diarréia foi efetuado somente em bezerros com até 90 dias de idade. Entre as propriedades estudadas por Machado Neto et al. ${ }^{31}$ observou-se um efeito positivo da desmama precoce sobre o índice de mortalidade que foi menor naquelas propriedades em que os bezerros eram desmamados até os três 
primeiros meses de vida.

Diarréia deve ser entendida como uma enfermidade multifatorial resultante da interação entre bezerro, meio ambiente, alimentação e agentes infecciosos ${ }^{4}$. Inúmeros fatores estão envolvidos na ocorrência de diarréia e o ambiente pode ser importante na transmissão de agentes infecciosos. No presente trabalho embora o objetivo não tenha sido identificar agentes causais de diarréia, mas a freqüência e os fatores envolvidos observou-se em aparente contradição, que a diarréia foi mais freqüente nas UPL em que os bezerros neonatos eram mantidos separados dos animais mais velhos $(22,2 \%)$, comparativamente aquelas em que não se efetuava a separação por faixa etária $(18,29 \%)$, mas sem diferença significativa $(\mathrm{p}=0,4011)$, e naquelas em que a higienização das instalações foi apenas ocasional $(17,1 \%)$, comparando-se com a higienização mais freqüente $(p=0,0326)$. Contudo, no momento em que se deseja avaliar isoladamente a importância de um fator sobre a ocorrência de enfermidades, outros fatores igualmente importantes podem ser negligenciados.

Neste sentido, buscando entender a menor freqüência de diarréia em ambientes higienizados ocasionalmente, constatou-se que em três UPL utilizava-se bezerreiro individual tipo casinha e em outras três, bezerreiro coletivo, elevado com piso ripado e separação dos animais recém nascidos. Comparativamente, a higiene foi mais freqüente em UPL que utilizavam bezerreiros coletivos que resultavam em maior volume de fezes acumuladas diariamente. Neste sentido sugerimos que a aglomeração de animais e o tipo de piso do bezerreiro podem exigir maior freqüência na higienização, porém a higienização mais freqüente não garante a eficiência no sentido de reduzir o aporte de agentes infecciosos ou os riscos de contaminação. E ainda, o stress e/ou competição entre os animais e a possibilidade de que os efeitos da higienização ocasional sejam minimizados por outras formas de manejo que exercem igual ou superior efeito sobre a ocorrência de diarréia devem ser considerados. Das instalações avaliadas por Machado Neto et al. ${ }^{31}$, a que apresentou menor taxa de mortalidade foi a "casinha individual", que segundo os autores diminui a difusão de enfermidades, facilita a limpeza, a desinfecção e o manejo dos animais, diminuindo significativamente os níveis de mortalidade.

No presente trabalho observou-se menores índices de diarréia entre os bezerros que receberam precocemente suplementação de volumoso, concentrado e mistura mineral, contudo sem diferença significativa entre os estratos $(p=0,6354)$, podendo-se atribuir esse fato a forma de suplementação registrada nas propriedades. Em todas as propriedades, o fornecimento de volumoso se limitava ao acesso ao pasto enquanto que o concentrado, a exceção das UPL que utilizavam o sistema de casinha, era fornecido em períodos restritos, em comedouros coletivos e em quantidade não calculada segundo o número de animais. Mistura mineral em quantidade, formulação e forma de administração adequada, foi observada somente em duas propriedades. As demais (3) forneceram mistura mineral após as ordenhas e em geral essa mistura deveria ser consumida por adultos e jovens simultaneamente, o que pode ter tornado ineficiente a sua utilização.

O consumo de alimentos sólidos, sobretudo concentrado, está diretamente relacionado ao desenvolvimento fisiológico do rúmen, sendo um dos é fundamentos para o desmame precoce. Resultados obtidos por Lima (1974), citados por Leite e Lima ${ }^{10}$ evidenciaram que a taxa de mortalidade é menor para o estrato de propriedades com rebanho menor e suplementação precoce de concentrado. Um estudo recente ${ }^{31}$ evidenciou que o fornecimento precoce de concentrado pode ser favorável ao desenvolvimento dos bezerros, resultando em menor taxa de mortalidade. Ainda que fisiologicamente a ingestão de volumoso em idas ocasionais ao pasto, não garanta o desenvolvimento do rúmen, para utilização eficiente de volumoso, na faixa etária estudada ${ }^{32}$ os dados obtidos 
no presente estudo confirmam a influência benéfica da suplementação precoce.

O conhecimento dos indicadores nacionais revelados no presente levantamento poderá se constituir em importantes subsídios para propostas de programas que visem suprir possíveis falhas de manejo na fase inicial de desenvolvimento do bezerro.

\section{Conclusões}

Embora a ocorrência de diarréia tenha sido menor entre os bezerros que permaneceram com a mãe após o parto por cerca de 24 horas, nas unidades de produção que utilizaram o sistema de aleitamento natural e naquelas propriedades em que os bezerros receberam alimentação suplementar na forma de volumoso e concentrado fornecidos no cocho, nenhum fator isoladamente pode ser considerado determinante sobre a incidência de diarréia em uma unidade de produção.

Diarréia é uma enfermidade complexa, com diversos fatores determinantes envolvidos, sendo importante implementar medidas estratégicas de controle e prevenção considerando as características individuais de cada propriedade, respeitando o manejo utilizado e fatores econômicos, de modo que seja viável a produção e a lucratividade da atividade pecuária na propriedade.

\title{
Frequency of diarrhea in dairy calves submitted to different breeding conditions in the border of Rio de Janeiro and Minas Gerais states, Brazil
}

\begin{abstract}
The main diseases affecting calves, and consequently, representing economic losses with treatment and mortality losses are diarrhea, tick borne diseases and pneumonia. In general, these diseases are related to poor environmental conditions and food hygiene, plus inadequate management. The present work aimed at estimate the frequency of diarrhea in dairy milk calves submitted to different breeding conditions. Twenty dairy milk type $C$ farms, located at the cities of Valença, Rio das Flores (RJ) and Rio Preto (MG), were visited from August of 1998 to July of 1999 and 1974 calves were examined. Statistical analysis of diarrhea frequency showed that the lowest occurrence of diarrhea was achieved in the following situations: to let the calves stayed with their mothers after born for at least 24 hours after delivery, use of natural milk feeding and also, to allow the calves to receive supplemental feeding. In general, these farms presented lower cows in lactation, lower milk production and familiar management, which contribute to higher levels of care.
\end{abstract}

\section{Referências}

1 BRUNING-FANN, C.; KANEENE, J. B. Environmental and management risk factors associated with morbidity and mortality in perinatal and pre-weaning calves: a review from an epidemiological perspective. Veterinary Bulletin, v. 62, p. 399-413, 1992.

2 VIRTALA, A. K. et al. Morbidity from nonrespiratory diseases and mortality in dairy heifers during the first three months of life. Journal of American Veterinary Medical Association, Ithaca, v. 208, p. 2043-2046, 1996.
Key words: Diarrhea.

Calves.

Colostrum. Management Hygiene.
3 BARRINGTON, G. M; GAY, J. M; EVERMANN, J. F. Biosecurity for neonatal gastrointestinal diseases. Veterinary Clinics of North American: Food Animal Practice, v. 18, n. 1, p. 7-34, 2002.

4 HALL, G. A; JONES, P. W.; MORGAN, J. H. Calf Diarrhea. In: ANDREWS, H. A.; BOYD, H.; BLOWEY, R.W. Bovine medicine diseases and husbandry of cattle. Oxford: Blackwell, 1992. p. 154-180.

5 MORTEO, C. G.; AWJA, A. S.; ESTRELLA, S. G. Estudio etiológico de los problemas diarreicos en becerros lactentes. Veterinaria Mexicana, v. 21, n. 4, p. 435-438, 1990. 
6 BACHMANN, P. A. Neue virale Durchfallerkrankungen beim kalb. Tierärztliche Umschau, v. 10, p. 524-526, 1977.

7 KANEENE, J. B.; HURD, H. S. The national animal health monitoring system in Michigan. III. Cost estimates of selected dairy cattle diseases. Preventive Veterinary Medicine, v. 8, p. 127-140, 1990

8 FIGUEIREDO, M. C. P. Alguns aspectos da situação sanitária bovina no município de Uberaba, Minas Gerais. 1979. 172 f. Dissertação (Mestrado) Universidade Federal de Minas Gerais, MG, 1979.

9 LANGENEGGER, J.; COELHO, N. M.; MENKE, L. G. Manejo deficiente, o maior problema da criação de bezerros. Biologia Campo, v. 262, n. 11, p. 60-64, 1974.

10 LEITE, R. C.; LIMA, J. D. Fatores sanitários que influenciam na criação de bezerros. Arquivos da Escola de Veterinária da UFMG, v. 34, n. 3, p. 485-492, 1982.

11 PRADO, E.; CRUZ, F. E. R.; VIANA, F. C. Problemas sanitários do rebanho de leite: percepção dos criadores. Arquivo Brasileiro de Medicina Veterinária e Zootecnia, v. 49, n. 1, p. 19-29, 1997.

12 SOUSA, M. V. et al. Aspectos clínicos e epidemiológicos da diarréia dos bezerros em Botucatu, SP. Revista Brasileira de Ciências Veterinárias, v. 7, n. 2, p. 74-77, 2000.

13 GONÇALVES, R. C. et al. Aspectos clínicos e epidemiológicos da broncopneumonia dos bezerros em Botucatu, SP. Revista Brasileira de Ciências Veterinárias, v. 7, n. 3, p. 144-147, 2000.

14 BOTTEON, R. C. C. M.; BOTTEON, P. T. L.; LÓSS, Z. G. Aspectos sanitários da pecuária leiteira na região do Médio Paraíba - RJ e MG. Revista Brasileira de Ciências Veterinárias, v. 8, n. 3, p. 141-143, 2001.

15 FEITOSA, F. L. F. et al. Transferência de imunidade passiva colostral e a morbidade e mortalidade de bezerros neonatos. Revista do CRMV-SP, v. 4, p. 9-15, 2001.

16 SILVA, L. A. F. et al. Importância do manejo no controle da mortalidade de bezerros em uma propriedade rural de exploração mista de bovinos. Revista Brasileira de Ciências Veterinárias, v. 8, p. 94 99, 2001.

17 MATTA, H. Influência da variação estacional na criabilidade de bezerros mestiços leiteiros. Pesquisa Agropecuária Brasileira, v. 8, n. 2, p. 39-42, 1973.

18 GOMES, E. F. C.; CARNEIRO, J. M. Subsídios para a programação do desenvolvimento da pecuária bovina mineira. Belo Horizonte: Imprensa da escola de Veterinária da UFMG, 1977. 167 p.

19 SNODGRASS, D. R. et al. A etiology of diarrhea in young calves. Veterinary Record, v. 119, p. 31-34, 1986.

20 OLIVEIRA, A. A.; PEDREIRA, P. A. S.; ALMEIDA, M. F. R. S. Doenças de bezerros. I. Diarréias bacterianas no Estado de Sergipe, Brasil. Arquivo Brasileiro de Medicina Veterinária e Zootecnia, v. 41, p. 213-222, 1989.

21 FAGAN, J. G.; DWYER, P. J.; QUINLAN, J. G. Factors that may affect the ocurrence of enteropathogens in the feces of diarrheic calves in Ireland. Irish Veterinary Journal, v. 48, p. 17-21, 1995.

22 ALVES, A.J. Ocorrência de enteropatógenos em bezerros diarréicos em fazendas de exploração leiteira. 1997. 55f. Dissertação (Mestrado) - Faculdade de Medicina Veterinária e Zootecnia - UNESP, 1997.

23 LANGONI, H. et al. Contribution to the study of diarrhea etiology in neonate dairy calves in São Paulo state, Brazil. Brazilian Journal of Veterinary Research and Animal Science, v. 41, p. 313-319. 2004.

24 OLIVEIRA FILHO, J.P. Diarréia em bezerros da raça Nelore criados extensivamente: estudo clínico e etiológico. 2006. 96 f. Dissertação (Mestrado) Faculdade de Medicina Veterinária e Zootecnia UNESP, 2006.

25 BENESI, F. J. Síndrome diarréia dos bezerros. Revista do CRMV-ES, v. 2, n. 3, p. 10-13, 1999.

26 JEREZ, J. A. et al. Detecção de rotavírus e coronavírus em fezes de bezerros neonatos com diarréia criados em São Paulo, Brasil. Arquivos do Instituto Biológico, v. 69, n. 2, p. 19-23, 2002.

27 DONOVAN, G. A.; DOHOOB, I. R.; BENNETTA, F. L. Cattle morbidity and mortality; Passive immunity. Preventive Veterinary Medicine, v. 34. n. 1, p. 31-46, 1998.

28 KOHARA, J.; TSUNEMITSU, H. Correlation between maternal serum antibodies and protection against bovine rotavirus diarrhea in calves. Journal of Veterinary Medical Science, v. 62, n. 3, p. 219-221, 2000.

29 GUTZWILLER A. Effect of colostrum intake on diarrhoea incidence in new-born calves. Schweiz Arch Tierheilkd, v. 144, n. 2, p. 59-64, 2002.

30 PRADO, E. Características sócio-econômicas e sanitárias da pecuária bovina do município de Divinópolis, MG. 1991. 112 f. Dissertação (Mestrado) - Universidade Federal de Minas Gerais, MG, 1991.

31 MACHADO NETO, R. et al. Levantamento do Manejo de Bovinos Leiteiros Recém-Nascidos: Desempenho e Aquisição de Proteção Passiva. Revista Brasileira de Zootecnia, v. 33, n. 6, p. 2323-2329, 2004.

$32 \mathrm{LUCCl}, \mathrm{C}$. Bovinos leiteiros jovens: nutrição, manejo, doenças. São Paulo: Nobel. 1989. 371 p.

33 NOCEK, J. E.; BRAUND, D. G.; WARNER, R. G. Influence of neonatal colostrum administration, immunoglobulin, and continued feeding of colostrum on calf gain, health and serum protein. Journal of Dairy Science, v. 67, n. 2, p. 319-333, 1984.

$34 \mathrm{GAY}, \mathrm{C}$. C. Colostrum research for healthier calves. 
Hoard's Dairyman, v. 139, n. 6, p. 256, 1994.

35 WITTUM, T. E.; PERINO, L. J. Passive immune status at postpartum hour 24 and long term health and performance of calves. American Journal of Veterinary Research, v. 56, n. 9, p. 1149-1154, 1995.

36 BORGES, A.S. Avaliação da eficácia da administração de plasma, por via intravenosa, como tratamento da falência de transferência de imunidade passiva em bezerros da raça Holandesa. 1997. 84 f. Dissertação (Mestrado) - Faculdade de Medicina Veterinária e Zootecnia, Universidade de São Paulo, São Paulo, 1997.

37 PERINO, L. J. A guide to colostrum management in beef cows and calves. Veterinary Medicine, v. 92, p. 75-82, 1997.

38 DANIELE, C. et al. Efeito de diferentes manejos no fornecimento prolongado de colostro sobre o comportamento imunológico e desempenho de bezerros leiteiros recém nascidos. Revista da Sociedade Brasileira de Zootecnia, v. 23, n. 2, p. 211 222, 1994.
39 DANIELE, C. et al. Efeito de diferentes manejos de fornecimento prolongado de colostro sobre os níveis de proteína e albumina séricas e desempenho de bezerras recém nascidas. Scientia Agricola, v. 5, n. 2, p. 381-388, 1994.

40 PENHALE, W. D. et al. Quantitative studies on immunoglobulin. II. Plasma immunoglobulin levels in market calves and theirs relationship to neonatal infection. Brazilian Journal of Veterinary Research and Animal Science, v. 126, n. 1, p. 30-37, 1970.

41 WILLIANS, M. R.; SPONDE, R. L.; THOMAS, L. H. Quantitative studies on bovine immunoglobulins. Veterinary Record, v. 96, n. 4, p. 81-84, 1975.

42 HALL, G. A; REYNOLDS, D. J.; MORGAN, J. H. Pathogenesis of diarrhea in rotavirus infected calves. In: WORLD VETERINARY CONGRESS. DISEASE OF CATTLE, WORLD ASSOCIATION BUIATRICS, 14. 1988, Palma de Mallorca. Proceedings...v. 1, p. 331335, 1988.

43 RADOSTITS, O. M. et al. Clínica veterinária. $9^{\mathrm{a}} \mathrm{ed}$ Rio de Janeiro: Guanabara Koogan, 2002. p. 56-59. 